\title{
Manejo de osteomielite mandibular em paciente pediátrico: relato de caso
}

\author{
Management of mandibular osteomyelite in a pediatric patient: case report \\ Tratamiento de osteomielita mandibular en paciente pediátrico: reporte de caso
}

Kalyne Kelly Negromonte Gonçalves ORCID: https://orcid.org/0000-0002-8600-9158 Universidade de Pernambuco, Brasil E-mail: kalyne.negromonte@upe.br

Thawan Lucas Rodrigues Mendonça ORCID: https://orcid.org/0000-0001-9399-4339

Universidade Federal de Pernambuco, Brasil E-mail: thawanlucasr@gmail.com

Vitória Helena Sales do Nascimento ORCID: https://orcid.org/0000-0003-4111-9393 Universidade de Pernambuco, Brasil E-mail:vitoria.sales@upe.br

Olímpio Francisco da Costa Neto ORCID: https://orcid.org/0000-0002-4298-9326

Universidade Federal de Pernambuco, Brasil E-mail: olimpiofcosta@hotmail.com

Demóstenes Alves Diniz

ORCID: https://orcid.org/0000-0001-5823-6364 Hospital da Restauração, Brasil E-mail: dinizdemostenes@gmail.com

Francisco Alves de Souza Júnior ORCID: https://orcid.org/0000-0002-3110-2953 Universidade de Pernambuco, Brasil E-mail:fasjunior94@gmail.com Marcelo Soares dos Santos ORCID: https://orcid.org/0000-0001-7262-6035 Universidade de Pernambuco, Brasil E-mail: marcelo.soares@upe.br Caio César Gonçalves Silva ORCID: https://orcid.org/0000-0002-7519-7894 Universidade de Pernambuco, Brasil E-mail: caio.cesar@upe.br

Allan Vinícius Martins de Barros ORCID: https://orcid.org/0000-0002-5818-1575 Universidade de Pernambuco, Brasil E-mail:allanmartinsodonto@gmail.com

Carlos Augusto Pereira do Lago ORCID: https://orcid.org/0000-0001-9457-714X Universidade de Pernambuco, Brasil E-mail: carlos.lago@upe.br

Belmiro Cavalcanti do Egito Vasconcelos ORCID: https://orcid.org/0000-0002-6515-1489 Universidade de Pernambuco, Brasil E-mail: belmiro.vasconcelos@upe.br

\section{Resumo}

A osteomielite é um processo inflamatório agudo ou crônico dos espaços medulares ou corticais do osso. Em sua maioria é causada por infecção bacteriana resultando em uma destruição lítica e expansiva do osso envolvido, com supuração e formação de sequestro ósseo. É rara em pacientes pediátricos e a prevalência é maior em pacientes do sexo masculino, sendo a mandíbula o osso mais acometido. O objetivo deste trabalho é relatar um caso clínico de uma criança com osteomielite, discutindo o correto diagnóstico, seu tratamento cirúrgico e protocolo farmacológico. Paciente do sexo feminino, 11 anos de idade, com quadro de aumento de volume em espaço mastigatório submandibular esquerdo após exodontia do elemento dentário 36, com presença de sinais flogísticos. Ao exame radiográfico apresentava lesão radiolúcida irregular compatível com sequestros ósseos, sugestivo de osteomielite. Protocolo farmacológico baseado em antibioticoterapia de amplo espectro foi instituído e cirurgicamente foi realizada limpeza e curetagem óssea. Sabe-se que a osteomielite é uma complicação comumente associada a pacientes imunodeprimidos, porém pode ocorrer eventualmente em pacientes hígidos, sendo o tratamento e diagnóstico precoce fundamental, principalmente em pacientes pediátricos, pois a mesma torna-se uma potencial causa para quadros 
infecciosos mais graves e complexos, podendo disseminar-se e alcançar estruturas nobres como os seios cavernosos, levando à morte.

Palavras-chave: Osteomielite; Criança; Mandíbula.

\begin{abstract}
Osteomyelitis is an acute or chronic inflammatory process in the medullary or cortical spaces of the bone. Most of it is caused by bacterial infection resulting in a lytic and expansive destruction of the involved bone, with suppuration and formation of bone sequestration. It is rare in pediatric patients and the prevalence is higher in male patients, with the mandible being the most affected bone. The objective of this work is to report a clinical case of a child with osteomyelitis, discussing the correct diagnosis, its surgical treatment and pharmacological protocol. Female patient, 11 years old, with enlarged volume in the left submandibular masticatory space after tooth extraction 36, with the presence of inflammatory signs. Radiographic examination showed an irregular radiolucent lesion compatible with bone sequestration, suggestive of osteomyelitis. Pharmacological protocol based on broad-spectrum antibiotic therapy was instituted and bone cleaning and curettage were surgically performed. It is known that osteomyelitis is a complication commonly associated with immunodepressed patients, but it can occasionally occur in healthy patients, and treatment and early diagnosis is fundamental, especially in pediatric patients, as it becomes a potential cause for more severe infectious conditions. and complex, being able to spread and reach noble structures like the cavernous sinuses, leading to death.
\end{abstract}

Keywords: Osteomyelitis; Child; Jaw.

\title{
Resumen
}

La osteomielitis es un proceso inflamatorio agudo o crónico en los espacios medulares o corticales del hueso. La mayor parte es causada por una infección bacteriana que da como resultado una destrucción lítica y expansiva del hueso afectado, con supuración y formación de secuestro óseo. Es raro en pacientes pediátricos y la prevalencia es mayor en pacientes varones, siendo la mandíbula el hueso más afectado. El objetivo de este trabajo es reportar un caso clínico de un niño con osteomielitis, discutiendo el diagnóstico correcto, su tratamiento quirúrgico y protocolo farmacológico. Paciente de sexo femenino, 11 años, con aumento de volumen en espacio masticatorio submandibular izquierdo tras extracción dentaria 36, con presencia de signos inflamatorios. El examen radiográfico mostró una lesión radiolúcida irregular compatible con secuestro óseo, sugestiva de osteomielitis. Se instituyó protocolo farmacológico basado en antibioterapia de amplio espectro y se realizó quirúrgicamente limpieza ósea y curetaje. Se sabe que la osteomielitis es una complicación comúnmente asociada con pacientes inmunodeprimidos, pero ocasionalmente puede ocurrir en pacientes sanos, y el tratamiento y diagnóstico precoz es fundamental, especialmente en pacientes pediátricos, ya que se convierte en una posible causa de enfermedades infecciosas más graves y complejas. , pudiendo extenderse y alcanzar estructuras nobles como los senos cavernosos, conduciendo a la muerte.

Palabras clave: Osteomielitis; Niño; Mandíbula.

\section{Introdução}

A osteomielite representa um processo infeccioso complexo, envolvendo os espaços medulares ósseos, evoluindo com notória progressão osteolítica em áreas vizinhas ao sítio inicial da infecção, estendendo-se e disseminando-se para a cortical óssea e em alguns casos, para o periósteo (Hawkins e Strauss, 2020; Neville, 2011).

Não existe predileção por faixa etária e a associação com pacientes pediátricos é rara. A literatura sugere que cerca de $75 \%$ dos casos envolvem pacientes do sexo masculino e o local anatômico mais acometido é a mandíbula, devido ao menor aporte sanguíneo em relação a maxila (Spazzin et al., 2004).

A osteomielite pode ser classificada em aguda ou crônica, se distinguindo de acordo com os aspectos clínicos e radiográficos. A osteomielite aguda ocorre ausência de alterações radiográficas, visto que seu curto tempo de evolução não é compatível com alterações a nível ósseo, apesar de clinicamente observar-se sintomatologia acentuada. Já na osteomielite crônica, é comum a detecção de destruição óssea no local da infecção, observado radiograficamente, ainda que, em alguns casos, os sintomas sejam mais moderados (Ellis, Hupp e Peterson, 2015; Masocatto, Oliveira e de Mendonça, 2017).

O principal fator etiológico associado a essa patologia é a infecção bacteriana, entretanto outros agentes podem ser desencadeantes, como a utilização de medicamentos quimioterápicos, antiangiogênicos, bifosfonatos, além da exposição a altas doses de radiação e estado de imunossupressão (Neville, 2011; Topazian, Goldberg e Rupp, 2006).

As manifestações clínicas comumente encontradas em pacientes com osteomielite durante o exame clínico são: aumento de volume, rubor, dor à palpação da região acometida e em alguns casos, fístula e sinais de infecção nos tecidos 
adjacentes, além de assimetria facial (Coello et al., 2020).

Quando presente, o aspecto radiográfico observa-se um osso de aspecto esclerosado, de alta densidade e radiopacidade, com áreas mal definidas de alta atividade osteolítica, denominadas de sequestros ósseos (Ellis, Hupp e Peterson, 20215; JB et al., 2018).

Conhecida como uma condição patológica de longa progressão, geralmente está associada à desfiguração e desestabilização óssea, mas que, com o avanço da terapêutica associada, sua incidência vem diminuindo significativamente (Spazzin et al., 2004). Apesar disso, quando não tratada, principalmente em pacientes pediátricos, a osteomielite torna-se uma potencial causa para quadros infecciosos mais graves e complexos, podendo alcançar, por exemplo, estruturas nobres como os seios cavernosos (Baltieri et al., 2014).

O tratamento indicado para a osteomielite consiste na remoção da fonte de infecção, drenagem e irrigação, geralmente associada à antibioticoterapia oral e/ou parenteral, e quando necessário, realiza-se a extração de tecido necrótico e desbridamento cirúrgico. Também podem ser adotadas terapias à laser e/ou oxigenioterapia hiperbárica (JB et al., 2018; Ribeiro et al., 2009; Spazzin et al., 2004).

Sendo assim, o presente trabalho objetiva relatar o caso clínico de uma paciente pediátrica que desenvolveu osteomielite após a extração dentária, bem como discutir a importância de um diagnóstico correto, bem como o atual manejo terapêutico dessa lesão.

\section{Metodologia}

O presente estudo corresponde a um relato de caso, caracterizando-se como um estudo descritivo e retrospectivo, utilizando-se de imagens para seu auxílio e ilustração, sendo conduzido da forma mais tradicional de estratégia de pesquisa, apoiado nas técnicas de observação direta e revisão de literatura, integrando-se de um método abrangente de coleta e análise de dados, compreendendo uma completa e clara descrição e discussão de fatores que vão desde o diagnóstico até o tratamento da condição (Pereira et al., 2018). Obedecendo as questões éticas que envolvem este tipo de pesquisa, de forma atinente à resolução $n^{\circ}$ 446/2012 aprovada pelo Conselho Nacional de Saúde, que rege as pesquisas e testes em seres humanos. Este estudo foi aprovado pela comissão de ética do Hospital da Restauração de acordo com a declaração de Helsinque, a responsável legal pela paciente assinou o termo de consentimento livre e esclarecido (TCLE) para participação na pesquisa, autorizando a utilização de dados clínicos-laboratoriais de seu caso clínico/cirúrgico e documentação fotográfica.

\section{Relato de caso}

Em março de 2018, uma criança do sexo feminino, 11 anos de idade, melanoderma, compareceu ao serviço de Cirurgia e Traumatologia Buco-Maxilo-Facial do Hospital da Restauração, Recife, Pernambuco, Brasil, com aumento de volume em região submandibular esquerdo após procedimento odontológico.

Durante exame clínico, a genitora informou que a paciente havia sido submetida à exodontia de dente 36 em consultório odontológico particular sob anestesia local há aproximadamente 03 meses. Negava ainda presença de comorbidades, alergias ou uso de medicamentos. 
Research, Society and Development, v. 10, n. 2, e52510212853, 2021

(CC BY 4.0) | ISSN 2525-3409 | DOI: http://dx.doi.org/10.33448/rsd-v10i2.12853

Figura 1. A- Vista Infero-superior da paciente/ B-Vista frontal da paciente evidenciando aumento de volume em região submandibular do lado esquerdo.
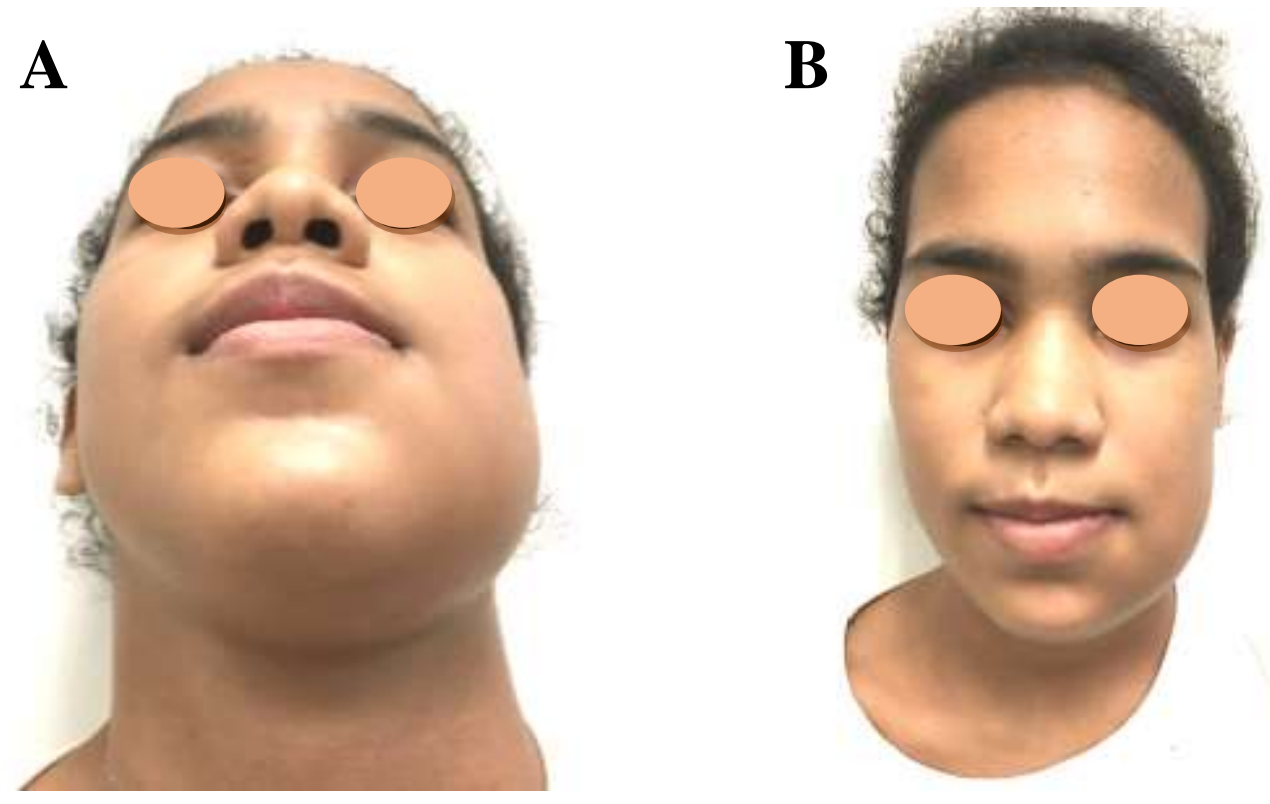

Fonte: Autores.

Ao exame físico a paciente apresentava aumento de volume endurecido à palpação em região submandibular esquerda (Figura 1A e 1B), sem ponto de flutuação extra-oral, sintomatologia dolorosa presente e intensa, trismo moderado, ausência de secreção purulenta, alvéolo remanescente com presença de tecido ploriferativo verrucoso (compatível com pólipo inflamatório) e ausência de linfonodomegalia.

Figura 2. Radiografia panorâmica dos maxilares sugerindo imagem radiolúcida irregular associada ao alvéolo dentário do elemento 36 .

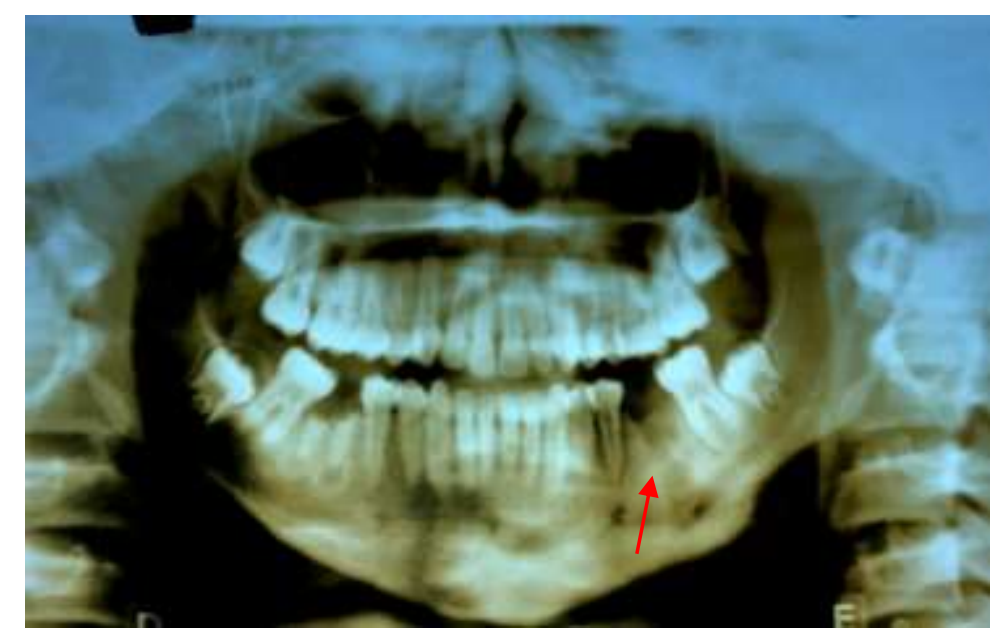

Fonte: Autores. 
Figura 3. Tomografia computadorizada de face sugerindo aumento de cortical vestibular e imagem hipodensa irregular em corpo mandibular esquerdo.

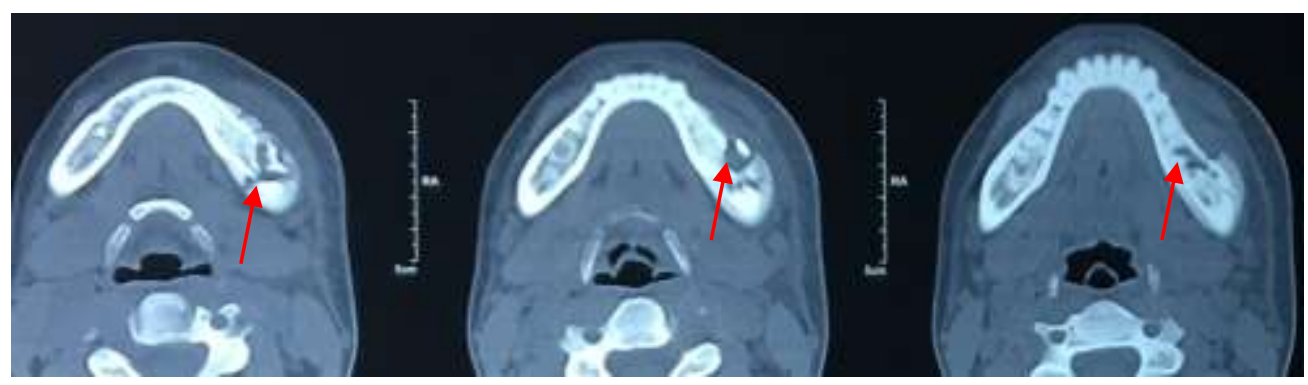

Fonte: Autores

Ao exame radiográfico (radiografia panorâmica dos maxilares) (Figura 2) sugeria presença de áreas radiolúcidas em região de corpo mandibular esquerdo, com proximidade do dente removido. A tomografia computadorizada de face (Figura 3) evidenciou áreas hipodensas e irregulares na superfície óssea, sendo compatível com áreas osteolíticas com aspecto semelhante a "ruído por traça", sugerindo processo inflamatório infeccioso (osteomielite).

O exame laboratorial sugeria presença de discreta leucocitose $\left(12.85\left[10^{\wedge} 3 \mathrm{u} / \mathrm{L}\right]\right)$. O tratamento adotado para o caso em questão foi antibioticoterapia (Ceftriaxona associado ao Metronidazol) (Triaxton®- Blau Farmacêutica S/A, São Paulo, Brasil; Flagyl®- Baxter Hospitalar Ltda, São Paulo, Brasil) por 07 dias, corticoterapia (Dexametasona)( Metaxon®- Ariston Inds. Químs. e Farms. Ltda, São Paulo, Brasil) por 03 dias e analgesia (Dipirona)(Climax®-Halex Istar Indústria Farmacêutica Ltda,Goiânia, Goiás, Brasil) por 03 dias através de via endovenosa. Após a regressão do processo infeccioso (07 dias), foi programada biópsia para diagnóstico definitivo do caso.

Figura 4. Acesso Vestibular-Mandibular esquerdo com exposição do sequestro ósseo.

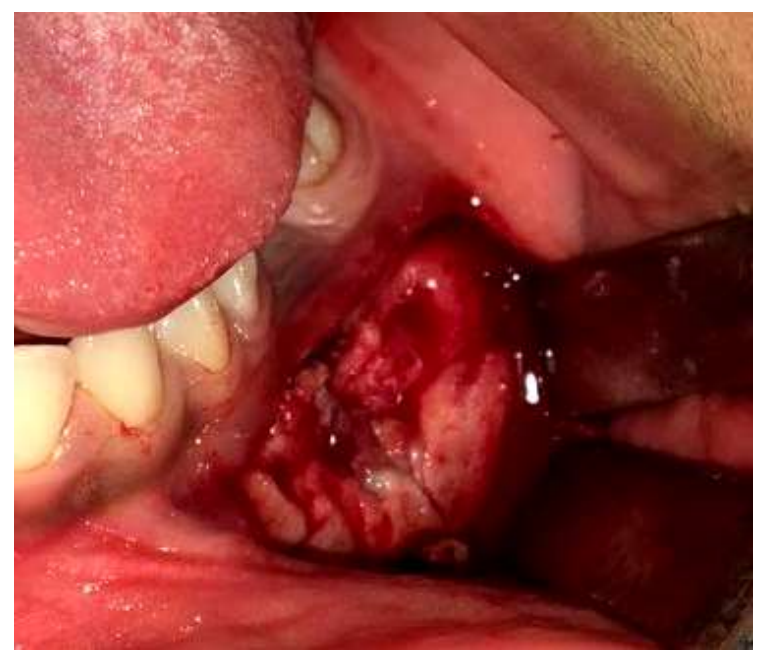

Fonte: Autores.

O procedimento cirúrgico foi realizado sob anestesia geral e intubação nasotraqueal. Inicialmente foi realizada punção aspirativa em fundo de vestíbulo mandibular esquerdo, com conteúdo aspirado negativo. Seguiu-se o bloqueio do nervo alveolar inferior esquerdo com anestésico local (Lidocaína 2\%) associado a vasoconstritor (1:100.000) (Nova DFL, Industry and Commerce S.A, Rio de Janeiro, Brasil), realização de acesso vestibular mandibular esquerdo (Figura 4), bem como biópsia excisional das lojas de sequestro ósseo em corpo mandibular esquerdo, curetagem, irrigação copiosa com soro fisiológico $0,9 \%$ 
(Linhamax®- Eurofarma Laboratórios. Ribeirão Preto, São Paulo, Brasil), e sutura com fio reabsorvível de Ácido Poliglicólico 910 (Vicryl®/Ethicon - Johnson \& Johnson, Somerville, Nova Jersey, EUA).

Figura 5. Tecido ósseo exibindo perda de osteócitos nas lacunas compatível com sequestro ósseo, sugestivo de Osteomielite.

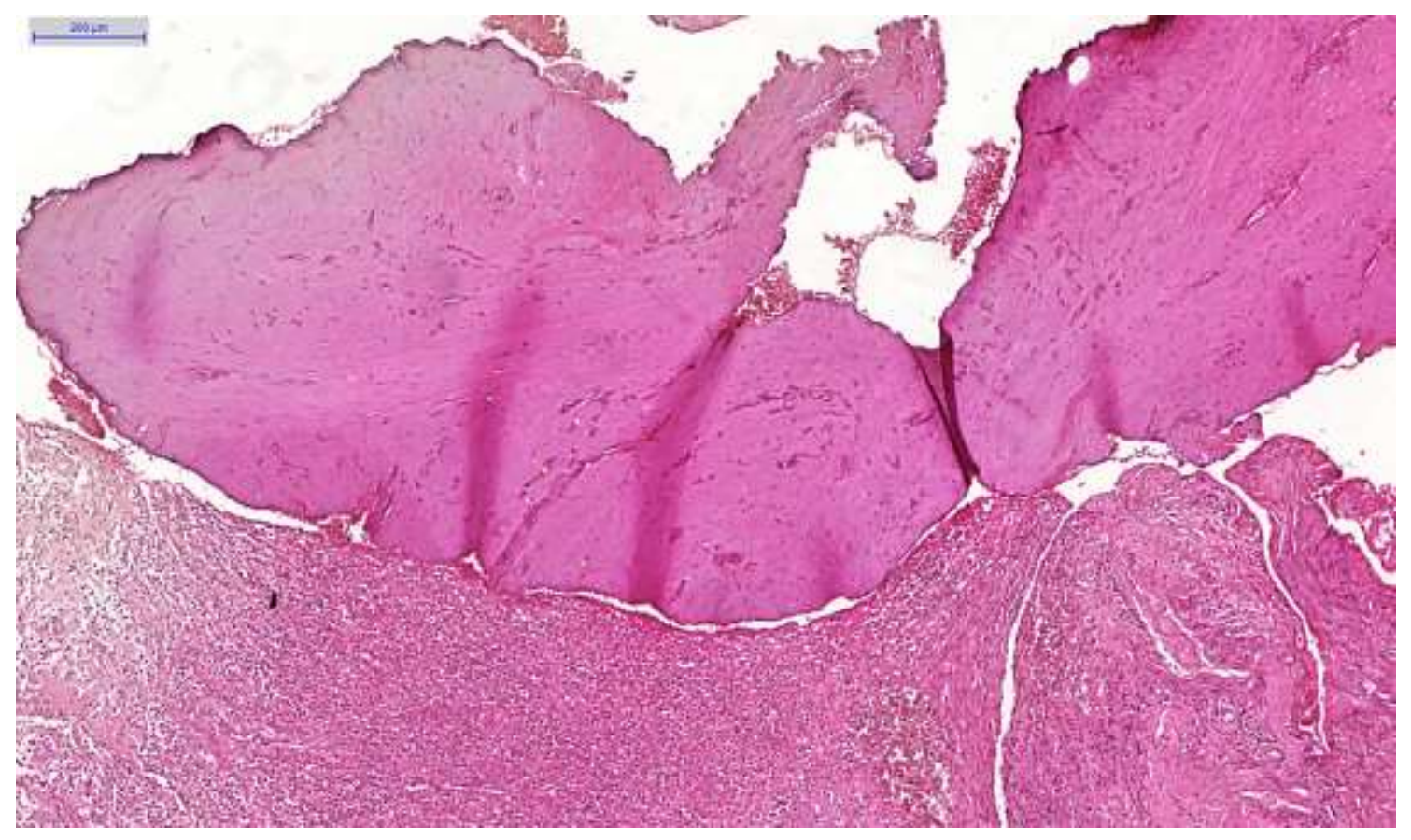

Fonte: Autores.

O material foi enviado ao serviço anatomopatológico do hospital que confirmou a hipótese diagnóstica de osteomielite levantada previamente a partir da visualização histológica de um espécime que apresentava em sua predominância tecido ósseo exibindo perda de osteócitos nas lacunas compatível com sequestro ósseo (Figura 5). Após 03 dias de acompanhamento na enfermaria com melhora clínica e laboratorial, a paciente recebeu alta hospitalar e foi encaminhada para controle ambulatorial.

Atualmente a paciente se encontra sem sequelas funcionais ou estéticas, ausência de sintomatologia dolorosa e acompanhamento radiográfico de controle de 02 anos, evidenciando ausência de recidiva.

\section{Resultados e Discussão}

A osteomielite é uma condição patológica que pode acometer os ossos da face, de forma que, invadindo o osso e seus espaços medulares, através de um processo infeccioso progressivo, se difunde e pode estender-se até os tecidos moles vizinhos, sendo distinguida de outros processos infecciosos que acometem a região maxilofacial através do envolvimento ósseo que é observado na evolução desta condição, onde um padrão osteolítico é estabelecido desde o foco infeccioso até as regiões adjacentes, características essas encontradas no presente caso em questão que convergem com a literatura (JB et al., 2018; Topazian, Goldberg e Rupp, 2006).

A literatura reporta que a osteomielite é rara em paciente infantil e do sexo feminino (Spazzin et al., 2004). Entretanto, reportamos um caso clínico incomum de uma paciente pediátrica, que após a realização de uma exodontia desenvolveu o processo osteolítico infeccioso. Além disso, o caso em questão acomete a mandíbula, corroborando assim a com a literatura. Esse fato pode ser justificado, visto que, a mandíbula, por receber seu suprimento vascular através da artéria alveolar inferior, e estando recoberta por uma matriz óssea cortical densa, impede o suprimento venoso por meio dos vasos periosteais, 
favorecendo quadros isquêmicos e consequentemente o estabelecimento de infecções como a osteomielite, como se concebeu na evolução do caso relatado, diferente da maxila, que conta com uma farta rede de vasos e diversas derivações arteriais, além de uma cortical mais delgada, o que facilita sua vascularização (Ellis, Hupp e Peterson, 2015; Spazzin et al., 2004).

O mecanismo de estabelecimento da osteomielite perpassa um processo de pressionamento da parede externa do osso acometido, fazendo com que os vasos sanguíneos daquela área sejam comprimidos, inviabilizando o suprimento sanguíneo e aumentando desta forma a pressão hidrostática, consequentemente a pressão sanguínea, resultando em necrose tecidual (Ellis, Hupp e Peterson, 2015; Zemann et al., 2011).

Como é ratificado pela literatura e confirmado pelos achados clínicos, alguns fatores e condições sistêmicas estão diretamente relacionadas ao estabelecimento de um quadro de osteomielite, como desordens hematológicas que impactem no suprimento sanguíneo ósseo, doenças sistêmicas crônicas, anemia, desnutrição, imunossupressão, etilismo, tabagismo, bem como a utilização de drogas antiangiogênicas, bifosfonatos, quimioterápicos e intravenosas (Lima et al., 2010; Neville, 2011; Spazzin et al., 2004; Topazian, Goldberg e Rupp, 2006).

A osteomielite pode apresentar origem hematogênica, traumática ou dentária, sendo a infecção bacteriana sua causa mais comum, principalmente quando associada a estados de imunossupressão (Masocatto, Oliveira e de Mendonça, 2017). No caso clínico em questão, a paciente não apresentava comorbidades que pudessem justificar a etiologia da osteomielite, sugerimos assim, que o trauma provocado pela exodontia representou a origem da patologia.

O diagnóstico de osteomielite é realizado através da coleta de informações durante a anamnese, associado a avaliação imaginológica, e investigação histopatológica, para assim se traçar o melhor plano de tratamento. Clinicamente, o paciente comumente apresenta febre, indisposição, fistulas intra-orais, abcessos, edema, rubor, queixa álgica local, otorréia purulenta e fétida, sinais de infecção nos tecidos adjacentes e linfoadenopatia (Coello et al, 2020; Pain et al., 2003; Spazzin et al., 2004).

Radiograficamente, não é incomum em casos de osteomielite aguda nos estágios iniciais de progressão, que se observe um aspecto radiográfico normal, já que não há presença notória de atividade osteolítica, apesar do paciente já apresentar clinicamente febre, dor, tumefação, leucocitose e linfoadenopatia (Masocatto, Oliveira e de Mendonça, 2017; Mercuri, 1991).

Já em osteomielites com um maior tempo de evolução, como neste caso ilustrativo, as expressões sintomatológicas clinicas se fazem menos presentes, já nos achados radiográficos, observamos o que chamamos de sequestros ósseos, que são fragmentos ósseos segregados da tábua óssea de origem devido a atividade osteolítica do processo infeccioso, essa área imaginológica característica é que vai direcionar a classificação desta entidade em uma osteomielite crônica (Masocatto, Oliveira e de Mendonça, 2017).

Além dos achados imaginológicos obtidos através das radiografias, realizou-se a avaliação a partir de tomografias computadorizadas, para que assim fosse possível analisar a infecção secundária que acomete os tecidos moles adjacentes ao foco infeccioso ósseo. Também podem ser requisitados exames como cintilografia óssea e ressonância magnética, para fins de identificação e limitação da área afetada (Bruder, Jundt e Eyrich, 2009; Schuknecht, 1997).

Ainda assim, para ter conhecimento detalhado e efetivo acerca dos agentes patológicos causadores destes quadros, faz-se necessária a análise histopatológica realizada a partir de amostra purulenta ou óssea da lesão em questão, que neste caso foi colhida durante a intervenção cirúrgica, mesmo sabendo que em alguns casos não será possível a distinção entre os casos crônicos e graves exclusivamente a partir destes estudos, fazendo-se necessária uma investigação mais detalhada (Bruder, Jundt e Eyrich, 2009).

Histologicamente, ao analisar-se um espécime correspondente a osteomielite, é comum observarmos a presença de um contingente supurativo associado a um infiltrado de neutrófilos, plasmócitos e macrófagos, bem como áreas de osteonecrose e trabéculas ósseas com atividade osteoblástica reduzida, além de tecidos fibrosos correspondentes a áreas de reparação, bem 
como áreas de neoformação óssea (Brasileiro Filho, 2011; Spazzin et al., 2004).

Embora possa haver pequenas modificações no tratamento da osteomielite, dependendo principalmente da sua classificação, os princípios gerais são semelhantes para a maioria dos casos, como obedecidos durante a abordagem desta paciente, ou seja, primordialmente a antibioticoterapia, que pode ser combinada, se necessário, ao tratamento cirúrgico como medidas interventivas. Deve-se avaliar também a questão sistêmica, já que os pacientes geralmente possuem déficits nos mecanismos de defesa, dessa forma, faz-se necessário o angariamento de uma opinião médica quando necessária (Ellis, Hupp e Peterson, 2015; Topazian, Goldberg e Rupp, 2006).

É de conhecimento que o tratamento cirúrgico compreende a remoção da causa, desbridamento e curetagem da lesão, bem como a remoção total dos sequestros ósseos e drenagem cirúrgica, como realizado neste caso, da mesma forma que, concomitante a isso, durante a abordagem cirúrgica, foram removidos os espécimes ósseos para avaliação histopatológica e angariamento do diagnóstico definitivo (Ellis, Hupp e Peterson, 2015; Masocatto, Oliveira e de Mendonça, 2017).

Os antimicrobianos de amplo espectro de ação são os geralmente eleitos para o tratamento medicamentoso da osteomielite, sabe-se que os mais relatados são a clindamicina, as penicilinas e as fluoroquinolonas, visto sua efetiva atuação sobre a flora das infecções odontogênicas e boa penetração óssea, sendo assim, concordante com a literatura, justifica-se a opção por utilizar ceftriaxona associada à clindamicina, já que ambos são largamente utilizados para o tratamento deste tipo de infecção complexa, mostrando-se efetivos (Ellis, Hupp e Peterson, 2015; Masocatto, Oliveira e de Mendonça, 2017).

Quando há atraso no diagnóstico, extensa necrose óssea, administração incorreta dos antibióticos, desbridamento cirúrgico inadequado e agravamento de déficits sistêmicos pré-existentes é comum que se estabeleça a cronicidade do quadro da osteomielite. Por isso, faz-se necessário o saber e a importância correspondente a variação existente relacionada a terapia medicamentosa para esta entidade, que varia de acordo com o seu grau de progressão e a microbiota existente (Ellis, Hupp e Peterson, 2015; Kumar et al., 2014).

\section{Considerações Finais}

Embora incomum, a osteomielite em paciente pediátrico merece atenção especial, visto que quando há atraso no diagnóstico, pode causar perdas dentárias precoces, deformidades faciais, podendo evoluir para complicações mais graves envolvendo até mesmo o globo ocular, e consequentemente se estendendo para o seio cavernoso, aumentando assim a morbimortalidade. Reforçamos a importância do Cirurgião Buco-Maxilo-Facial no reconhecimento e manejo da lesão, bem como a necessidade de desenvolvimento de estudos que abordem e investiguem protocolos medicamentosos, cirúrgicos e manejo de complicações para casos deste tipo, uma vez que estes tópicos não são apresentados satisfatoriamente na literatura.

\section{Agradecimentos}

Os autores agradecem à Coordenação de Aperfeiçoamento de Pessoal de Nível Superior (CAPES), Conselho Nacional de Desenvolvimento Científico e Tecnológico (CNPq) e Hospital da Restauração da cidade de Recife.

\section{Financiamento}

Este trabalho recebeu apoio financeiro das agências de fomento brasileiras Coordenação de Aperfeiçoamento de Pessoal de Nível Superior (CAPES) e do Conselho Nacional de Desenvolvimento Científico e Tecnológico (CNPq).

\section{Conflito de interesses}

Os autores não têm conflito de interesses a declarar. 
Research, Society and Development, v. 10, n. 2, e52510212853, 2021

(CC BY 4.0) | ISSN 2525-3409 | DOI: http://dx.doi.org/10.33448/rsd-v10i2.12853

\section{Referências}

Baltieri, B. R., Gabrielli, M. A. C., Gabrielli, M. F. R., Pereira Filho, V. A., Lopes, F. S., \& Leite, V. A. (2014). Osteomielite em mandíbula de criança. Revista de Odontologia da UNESP, 43(Especial), 0-0.

Brasileiro Filho, G. B. (2011). Patologia. 8. Ed. Rio De Janeiro.

Bruder, E., Jundt, G., \& Eyrich, G. (2009). Pathology of osteomyelitis. In Osteomyelitis of the Jaws (pp. 121-133). Springer, Berlin, Heidelberg.

Coello, E. M. P., Lúa, I. M. A., Moyano, D. M. C., \& Rodríguez, J. D. C. (2020). Osteomielitis aguda: manifestaciones clínicas, diagnóstico y tratamiento. RECIMUNDO, 4(1 (Esp)), 210-218.

Ellis III, E., Hupp, J. R., \& Peterson, L. J. (2015). Cirurgia oral e maxilofacial contemporânea. Rio de Janeiro.

Hawkins, DR e Strauss, RA (2020). Osteomielite. Musculoskeletal Infections: A Clinical Case Book, 111.

JB, A., Lima Fonseca, K. C., Queiroz Danda, T. F., de Sousa Teixeira, A. L., \& Azenha, M. R. (2018). Suppurative Chronic Osteomyelitis: Case Report. International Journal of Biomedical Investigation, 1(2).

Kumar, V., Abbas, A. K., Fausto, N., \& Aster, J. C. (2014). Robbins and Cotran pathologic basis of disease, professional edition e-book. Elsevier health sciences.

Lima, E. D. N. D. A., Carvalho, C. H. P. D., Pereira, J. D. S., Medeiros, A. M. C. D., Galvão, H. C., \& Germano, A. R. (2010). Report of Diffuse Sclerosing Osteomyelitis in a diabetic patient. Revista de Cirurgia e Traumatologia Buco-maxilo-facial, 10(2), 19-23.

Masocatto, D. C., Oliveira, M. M., \& de Mendonça, J. C. G. (2017). Osteomielite crônica mandibular: relato de caso. ARCHIVES OF HEALTH INVESTIGATION, 6(2)

Mercuri, L. G. (1991). Acute osteomyelitis of the jaws. Oral and maxillofacial surgery clinics of North America, 3(2), 355-365.

Neville, B. (2011). Patologia oral e maxilofacial. Elsevier Brasil.

Paim, L. B., Liphaus, B. L., Rocha, A. C., Castellanos, A. L., \& Silva, C. A. (2003). Chronic recurrent multifocal osteomyelitis of the mandible: report of three cases. J Pediatr (Rio J), 79(5), 467-70.

Pereira, A. S., Shitsuka, D. M., Parreira, F. J., \& Shitsuka, R. (2018). Metodologia da pesquisa científica.

RibeiroI, A. L. R., de Oliveira MendesII, F. R., de MeloII, M. M., JúniorI, J. T. C., \& PontesIV, H. A. R. (2009). Tratamento da osteomielite supurativa crônica de mandíbula em criança com curto período de hospitalização. Rev. Cir. Traumatol. Buco-Maxilo-Facial, 9, 9-16.

Schuknecht, B. F., Carls, F. R., Valavanis, A., \& Sailer, H. F. (1997). Mandibular osteomyelitis: evaluation and staging in 18 patients, using magnetic resonance imaging, computed tomography and conventional radiographs. Journal of Cranio-Maxillofacial Surgery, 25(1), 24-33.

Spazzin, A. O., Camargo, B., De Conto, F., Flores, M. E., \& Rovani, G. (2004). Osteomielite dos maxilares. Rev Med HSVP, $16,23-7$.

Topazian, R. G., Goldberg, M. H., \& Rupp, J. R. (2006). Infecções orais e maxilofaciais. Santos.

Zemann, W., Feichtinger, M., Pau, M., \& Kärcher, H. (2011). Primary osteomyelitis of the mandibular condyle-a rare case. Oral and maxillofacial surgery, 15(2), 109-111. 